\title{
OBTENÇÃO DE PERMANGANATO A PARTIR DO DIÓXIDO DE MANGANÊS PRESENTE EM PILHAS ZINCO-CARBONO E ALCALINAS USADAS
}

\section{ARTIGO ORIGINAL}

RODRIGUES, Aldimar Machado ${ }^{1}$

RODRIGUES, Jocelia Silva Machado ${ }^{2}$

RODRIGUES, Aldimar Machado. RODRIGUES, Jocelia Silva Machado. Obtenção de permanganato a partir do dióxido de manganês presente em pilhas zincocarbono e alcalinas usadas. Revista Científica Multidisciplinar Núcleo do Conhecimento. Ano 05, Ed. 08, Vol. 09, pp. 143-155. Agosto de 2020. ISSN: 24480959, Link de acesso: https://www.nucleodoconhecimento.com.br/quimica/obtencaode-permanganato

\section{RESUMO}

O manganês é um dos metais presentes em grande quantidade nas pilhas alcalinas e zinco-carbono. Este metal é um dos principais componentes da pasta eletrolítica dessas pilhas e encontra-se na forma de dióxido de manganês. Desse modo, tornase viável um processo de reciclagem da pasta eletrolítica das pilhas com o intuito de obter o dióxido de manganês e, a partir dele, adquirir substâncias com outros estados de oxidação do metal. O permanganato de potássio é um composto de manganês bastante utilizado, apresentando aplicação em química analítica por ser um excelente agente oxidante de matéria orgânica. Este trabalho objetivou converter o dióxido de

${ }_{1}$ Mestrando em Química pela Universidade Federal do Sul e Sudeste do Pará (Unifesspa) e professor do Instituto Federal de Educação, ciência e Tecnologia do Pará (IFPA) - Campus Altamira.

${ }^{2}$ Mestranda em Química pela Universidade Federal do Sul e Sudeste do Pará (Unifesspa) - Campus Marabá. 
manganês de pilhas usadas em Permanganato de Potássio. Para isso, a pasta eletrolítica dos dispositivos foi extraída e fundida juntamente com Hidróxido de Potássio, obtendo-se compostos com manganês nos estados de oxidação V e VI, e estes foram posteriormente oxidados a permanganato. O método proporcionou obtenção rendimento em massa de solução de permanganato de, aproximadamente, $25 \%$ em relação ao material colhido da pilha. E pureza de, aproximadamente $15 \%$ para o $\mathrm{KMnO}_{4}$ liofilizado. Concluiu-se que é possível obter Permanganato de potássio a partir da oxidação do Dioxido de Manganêns de pilhas descartadas.

Palavras-chave: Pilha, permanganato, oxidação.

\section{INTRODUÇÃO}

Uma das problemáticas da sociedade atual em relação ao desenvolvimento sustentável é a de como descartar corretamente o chamado lixo tecnológico. Denomina-se lixo tecnológico todo aquele que é gerado a partir de aparelhos eletrodomésticos ou eletrônicos, incluindo pilhas e baterias (VIANA, 2008).

O descarte de pilhas em lixões comuns não é a maneira correta de tratar esse lixo, podendo levar a sérios problemas ambientais, além de apresentam características de corrosividade, reatividade e toxicidade, tornando-as resíduos perigosos (VIEIRA et al, 2013). Esses dispositivos apresentam em sua composição metais pesados que uma vez presente em quantidades apreciáveis nos organismos vivos podem ser letais, como, por exemplo, o mercúrio, metal que pode afetar vigorosamente a saúde humana atacando o fígado, o cérebro e prejudicando o desenvolvimento de fetos (SILVA E ANDRADE, 2018).

Segundo Campiotti e Giordano (2014), a primeira pilha surgiu por volta de 1800, através dos estudos do cientista Alessandro Volta. Basicamente, a pilha pode ser definida como um dispositivo eletroquímico que possui a capacidade de converter energia química em energia elétrica, por isso diz-se que são "acumuladores" de energia. As pilhas possuem um anodo (eletrodo negativo) e um catodo (eletrodo positivo), possui ainda a pasta eletrolítica, onde encontra-se o Dióxido de Manganês. 
Hoje, existem vários centros de coleta de pilhas e baterias usadas, onde esses dispositivos são recolhidos e enviados às indústrias, que reutilizam os materiais que as compõem. Isso ocorre devido a pressões das novas legislações ambientais. No Brasil, o Conselho Nacional do Meio Ambiente (CONAMA) tem baixado resoluções que pressionam as indústrias a desenvolverem práticas sustentáveis.

Um dos metais presentes em grande quantidade nas pilhas alcalinas e zinco-carbono é o manganês. Esse metal é um dos principais componentes da pasta eletrolítica dessas pilhas e encontra-se na forma de dióxido de manganês $\left(\mathrm{MnO}_{2}\right)$. Por isso, tornase viável a reciclagem das pilhas para a extração da pasta eletrolítica e aplicação do dióxido de manganês para a obtenção de compostos com outros estados de oxidação do metal, bem como sua forma metálica (RASCIO et al., 2010).

O permanganato de potássio é um composto de manganês bastante utilizado. Essa substância apresenta aplicação em química analítica por ser um excelente agente oxidante de matéria orgânica (ARAÚJO, 2013). O permanganato é um catalisador eficiente para a oxidação de alquenos e álcoois. É possível utilizar esse agente oxidante em sínteses orgânicas objetivando adquirir ácidos carboxílicos e cetonas a partir de álcoois (ZORZANELLI e MURI, 2014).

Desse modo, torna-se promissora uma técnica que permita converter o dióxido de manganês de pilhas alcalinas e zinco-carbono em permanganato. Este trabalho tem como objetivo a obtenção de permanganato a partir do dióxido de manganês presente em pilhas alcalinas e zinco-carbono para ser empregado em procedimentos analíticos de aulas práticas de química. 


\section{PROCEDIMENTOS EXPERIMENTAIS}

\subsection{TRATAMENTO DA PASTA ELETROLÍTICA COM SOLUÇÃO 8 MOLAR DE KOH}

Primeiramente foi realizada a desmontagem de uma pilha zinco-carbono $D$ da Panasonic e extraída a pasta eletrolítica da mesma. A pasta eletrolítica retirada da pilha foi $58,780 \mathrm{~g}$.

Em seguida foi realizado tratamento dessa pasta, retirando-se uma alíquota de 20 gramas do material recolhido da pilha. Para o tratamento desse material, foi preparada $100 \mathrm{~mL}$ de uma solução 8 molar de $\mathrm{KOH}$. A pasta eletrolítica foi misturada com a solução 8 molar de $\mathrm{KOH}$ em um béquer de plástico, pois o hidróxido ataca o vidro, e em seguida a mistura foi levada ao agitador magnético e deixada durante 27,5 horas, para que houvesse uma maior homogeneização da mistura de pasta eletrolítica e solução de hidróxido de potássio. No passo seguinte, a mistura foi filtrada a vácuo e, para eliminação da umidade, o resíduo sólido obtido foi levado até a estufa à uma temperatura aproximada de $100^{\circ} \mathrm{C}$, onde ficou por 24 horas.

\subsection{FUSÃO DA PASTA ELETROLÍTICA COM KOH}

Foram preparadas quatro amostras contendo a pasta eletrolítica com o intuito de obter soluções de permanganato $\left(\mathrm{MnO}_{4}^{-}\right)$. Os béqueres com as amostras foram nomeados A, B, C e D. As amostras foram feitas usando a pasta eletrolítica que foi tratada com solução 8 molar de $\mathrm{KOH}$ e o material retirado diretamente da pilha (não tratada). No béquer $\mathrm{A}$ foram colocados 1 grama de pasta eletrolítica (fonte de $\mathrm{MnO}_{2}$ ) não tratada juntamente com 1,6 gramas de hidróxido de potássio $(\mathrm{KOH})$; No béquer $B$ foram colocados 1 grama de pasta eletrolítica não tratada juntamente com 2 gramas de nitrato de sódio $\left(\mathrm{NaNO}_{3}\right)$ e 1,6 gramas hidróxido de potássio $(\mathrm{KOH})$; no béquer $\mathrm{C}$ foram colocados 1 grama de pasta eletrolítica tratada juntamente com 2 gramas de nitrato de sódio e 1,6 gramas de hidróxido de potássio $(\mathrm{KOH})$; no béquer $\mathrm{D}$ foram colocados 1 grama de pasta eletrolítica tratada juntamente com 1,6 gramas de 
hidróxido de potássio $(\mathrm{KOH})$. Os valores em massa de reagentes foram atribuídos com base nas estequiometrias das reações.

Tabela 1: proporções dos reagentes

\begin{tabular}{|c|c|c|c|c|}
\hline & $\begin{array}{l}\text { Pasta eletrolítica } \\
\text { tratada }\end{array}$ & $\begin{array}{lll}\text { Pasta eletrolítica não } & \text { natada } & \\
\text { tratad } & \end{array}$ & $\mathrm{KOH}$ & $\mathrm{NaNO}_{3}$ \\
\hline A & & $1 \mathrm{~g}$ & $1,6 \mathrm{~g}$ & \\
\hline B & & $1 \mathrm{~g}$ & $1,6 \mathrm{~g}$ & $2 g$ \\
\hline C & $1 \mathrm{~g}$ & & $1,6 \mathrm{~g}$ & $2 g$ \\
\hline D & $1 \mathrm{~g}$ & & $1,6 \mathrm{~g}$ & \\
\hline
\end{tabular}

Fonte: o autor (2019)

As misturas contidas em cada um dos béqueres foram pulverizadas, transferidos para respectivos cadinhos de porcelana e em seguida levados à mufla, onde foram submetidos a uma temperatura de $850^{\circ} \mathrm{C}$ durante 6 horas. Retiradas as amostras da mufla, esperou-se até o material esfriar e, em seguida, o solubilizou em água suficiente, obtendo-se $100 \mathrm{ml}$ de solução para cada uma das amostras.

\subsection{OXIDAÇÃO DOS MANGANATOS OBTIDOS PELA FUSÃO DA PASTA ELETROLÍTICA COM KOH}

\subsubsection{OXIDAÇÃO DO $\mathrm{MNO}_{4}{ }^{2-}$ A $\mathrm{MNO}_{4}{ }^{-}$POR SOLUÇÃO DE $\mathrm{NAHCO}_{3}$ 0,9 MOL.L-1}

Uma alíquota de $2 \mathrm{~mL}$ de cada uma das soluções $\mathrm{A}, \mathrm{B}, \mathrm{C}$ e D foram transferidas para tubos de ensaio. Então foi adicionado a cada tubo de ensaio $1,5 \mathrm{~mL}$ de solução 0,9 mol.L-1 de bicarbonato de sódio $\left(\mathrm{NaHCO}_{3}\right)$. O conteúdo dos tubos de ensaio com as soluções $A, C$ e $D$, que apresentaram mudanças significativas, passaram a ser denominadas $A_{1}, C_{1}$ e $D_{1}$. 


\subsubsection{OXIDAÇÃO DO $\mathrm{MNO}_{4}{ }^{2-}$ A $\mathrm{MNO}_{4}^{-}$POR SOLUÇÃO $\mathrm{DE} \mathrm{H}_{2} \mathrm{SO}_{4}$ CONCENTRADO (6,0 MOL.L-1)}

Foi retirada uma alíquota de $2 \mathrm{~mL}$ de cada uma das soluções $\mathrm{A}, \mathrm{B}, \mathrm{C}$ e D e transferidas para tubos de ensaio e adicionado a cada tubo de ensaio uma gota de solução 6,0 mol. $L^{-1}$ de ácido sulfúrico. $O$ conteúdo dos tubos de ensaio com as soluções $A, C$ e $D$, que apresentaram mudanças significativas, passaram a ser denominadas $A_{2}, C_{2}$ e $D_{2}$.

\subsection{ANÁLISE ESPECTROFOTOMÉTRICA DAS AMOSTRAS}

Foi preparada uma solução padrão de permanganato $\left(\mathrm{MnO}_{4}^{-}\right)$para análises espectrofotométricas objetivando encontrar o comprimento de onda máximo de absorção do permanganato e comparar com os resultados das análises das amostras $A_{1}, C_{1}, D_{1}, A_{2}, C_{2}$ e $D_{2}$ no espectrofotômetro. Encontrado o comprimento de onda máximo de absorção do $\mathrm{MnO}_{4}^{-}$, a solução de permanganato de potássio estoque do laboratório foi diluída em cinco concentrações diferentes $\left(5,0 \times 10^{-5}, 1,0 \times 10^{-4}, 2,0 \times\right.$ $10^{-4}, 3,0 \times 10^{-4}$ e $4,0 \times 10^{-4}$ mol.L-1 ) e levadas ao espectrofotômetro, onde foram analisadas suas respectivas absorbâncias no comprimento de onda máximo de absorção verificado anteriormente. A partir dos resultados, foi feito uma curva de calibração para encontrar a absortividade molar do permanganato e, assim poder encontrar as concentrações do íon nas soluções das amostras.

\subsection{LIOFILIZAÇÃO}

Para realizar o processo de liofilização, preparou-se $15 \mathrm{~mL}$ de uma solução 0,1 mol.L1 de permanganato de potássio, estoque do laboratório, congelou-a em uma placa de Petri, obtendo uma pastilha de aproximadamente um centímetro de espessura. $\mathrm{O}$ material foi levado a uma das bandejas do liofilizador, onde ocorreu o processo.

Observado o processo de liofilização da solução de permanganato de potássio estoque do laboratório, realizou-se a liofilização das soluções obtidas do dióxido de manganês da pasta eletrolítica das pilhas. Para isso, congelou-se $15 \mathrm{~mL}$ de solução 0,098 mol.L-1 (concentração aproximada determinada por análise 
espectrofotométrica) do permanganato de potássio obtido da oxidação de $\mathrm{Mn}(\mathrm{VI})$ à $\mathrm{Mn}$ (VII) por solução 0,9 mol.L-1 de $\mathrm{NaHCO}_{3}$ e $15 \mathrm{~mL}$ de solução $0,098 \mathrm{~mol}^{-\mathrm{L}^{-1}}$ do permanganato de potássio obtido da oxidação de $\mathrm{Mn}(\mathrm{VI})$ à $\mathrm{Mn}(\mathrm{VII})$ por solução de ácido sulfúrico concentrada $\left(6,0\right.$ mol. $\left.\mathrm{L}^{-1}\right)$ em respectivas placas de Petri, obtendo pastilhas de aproximadamente um centímetro de espessura.

\section{RESULTADOS E DISCUSSÃO}

\subsection{OBTENÇÃO DO PERMANGANATO}

Após retirar as amostras de pasta eletrolítica da mufla e solubilizá-las em água, observou-se que amostras A, C e D apresentaram soluções de coloração esverdeada e a amostra $B$ apresentou solução de coloração bege. O manganês, que se encontra no grupo 7 e período 4 da tabela periódica, com número atômico 25 e configuração eletrônica $1 s^{2}, 2 s^{2}, 2 p^{6}, 3 s^{2}, 3 p^{6}, 4 s^{2}, 3 d^{5}$, exibe grande faixa de estados de oxidação, indo de $-3 a+7$. São 11 estados de oxidação, mas o mais estável é o +2 (TABELA PERIÓDICA). As cores dos íons variam em função do seu número de oxidação. Compostos com $\mathrm{Mn}^{2+}$ se apresentam com uma tonalidade rósea; com $\mathrm{Mn}^{3+}$ e $\mathrm{Mn}^{4+}$, apresentam coloração preta; com $\mathrm{Mn}^{5+}$ (manganatos), exibem coloração marrom; com $\mathrm{Mn}^{6+}$ (manganatos), tem cor verde e com $\mathrm{Mn}^{7+}$ tem cor púrpura. Desse modo, é possível deduzir que as soluções $A, C$ e $D$ apresentam manganês em estado de oxidação VI (manganato de potássio, $\mathrm{K}_{2} \mathrm{MnO}_{4}$ ) e a solução $B$ apresenta manganês no estado de oxidação $\mathrm{V}$ (manganato de potássio, $\mathrm{K}_{3} \mathrm{MnO}_{4}$ ) (PRATES et al., 2011; DA ROCHA e AFONSO, 2012).

Os resultados obtidos assemelham-se aos encontrados na literatura. Segundo Rocha e Afonso (2012), parte do processo de obtenção do permanganato de potássio a partir do dióxido de manganês ocorre pela pulverização e fusão do $\mathrm{MnO}_{2}$ juntamente com $\mathrm{KOH}$ expostos ao ar ou na presença de um agente oxidante forte, na maioria das vezes nitrato de potássio $\left(\mathrm{KNO}_{3}\right)$. A temperatura necessária para a fusão dessa mistura deve ser bastante elevada, uma vez que as duas substâncias apresentam elevados pontos de fusão (ponto de fusão do $\mathrm{KOH}: 406{ }^{\circ} \mathrm{C}$; ponto de $\mathrm{MnO}_{2}: 535^{\circ} \mathrm{C}$ ). 
Segundo Afonso et al. (2003), a reação que ocorre quando $0 \mathrm{MnO}_{2}$ é fundido juntamente com a base hidróxido de potássio é:

\section{$1 / 2 \mathrm{O}_{2}+\mathrm{MnO}_{2}+2 \mathrm{KOH} \longleftrightarrow \mathrm{K}_{2} \mathrm{MnO}_{4}+\mathrm{H}_{2} \mathrm{O} \uparrow$}

Na presença de ácido sulfúrico ou bicarbonato de sódio, o $\mathrm{Mn}^{6+}$ do manganato $\left(\mathrm{MnO}_{4}{ }^{2-}\right.$ ) é oxidado a $\mathrm{Mn}^{7+}$, dando origem ao permanganato $\left(\mathrm{MnO}_{4}^{-}\right)$.

Quando as amostras A, C e D foram tratadas com solução 0,9 mol.L-1 de $\mathrm{NaHCO}_{3}$, verificou-se o surgimento de coloração púrpura, cor característica de soluções de permanganato, nas amostras $A, C$ e $D$, que passaram a ser chamadas de $A_{1}, C_{1}$ e $D_{1}$, para procedimentos posteriores. $A$ amostra $B$ não apresentou mudanças. Com isso é possível supor que a solução de $\mathrm{NaHCO}_{3}$ é eficiente para oxidar $\mathrm{Mn}^{6+}$ a $\mathrm{Mn}^{7+}$, obtendo-se o permanganato.

Quando as amostras A, C e D foram tratadas com ácido sulfúrico concentrado, verificou-se o surgimento de coloração púrpura, cor característica de soluções de permanganato, nas amostras $A, C$ e $D$, que passaram a ser chamadas de $A_{2}, C_{2}$ e $D_{2}$, para procedimentos posteriores. $A$ amostra $B$ não apresentou mudanças. Com isso é possível concluir que a solução de $\mathrm{H}_{2} \mathrm{SO}_{4}$ é eficiente para oxidar $\mathrm{Mn}^{6+}$ a $\mathrm{Mn}^{7+}$, obtendo o permanganato.

Após as análises das amostras $A_{1}, A_{2}, D_{1}, D_{2}, C_{1}$ e $C_{2}$ no espectrofotômetro, foram feitos gráficos de comprimento de onda versus absorbância para comparar com o resultado da análise da solução estoque de concentração conhecida de permanganato de potássio. Todas as seis amostras apresentaram máximo de absorção em $520 \mathrm{~nm}$, como mostram as figuras 1 e 2 . 
Figura 1: comprimento de onda máximo de absorção das amostras A1 (azul), C1 (roxo) e D1 (verde) é $520 \mathrm{~nm}$, indicando a presença do permanganato.

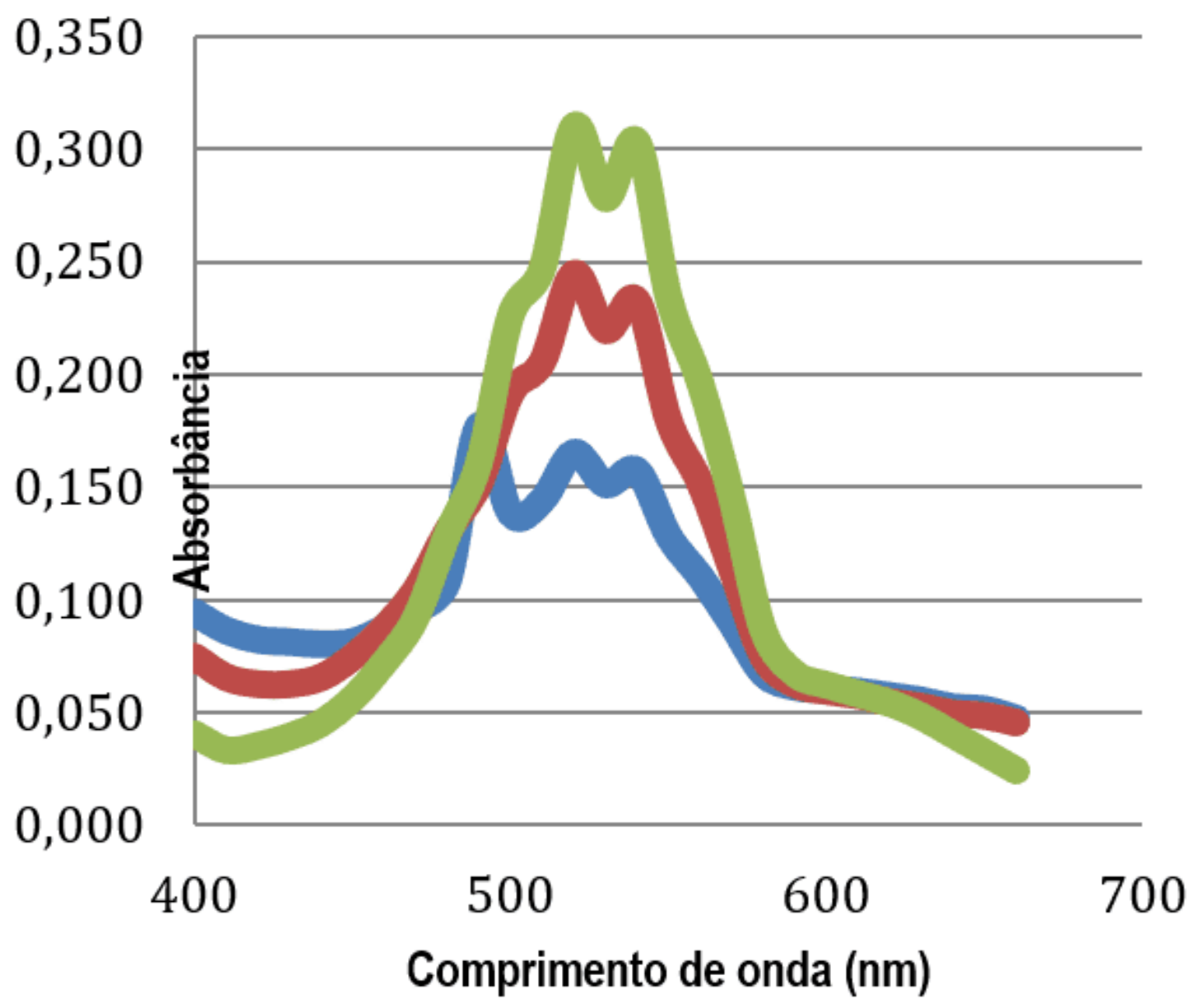

Fonte: o autor (2019) 
Figura 2: comprimento de onda máximo de absorção das amostras $A_{2}$ (azul), $C_{2}$ (roxo) e $D_{2}$ (verde) é $520 \mathrm{~nm}$, indicando a presença do permanganato.

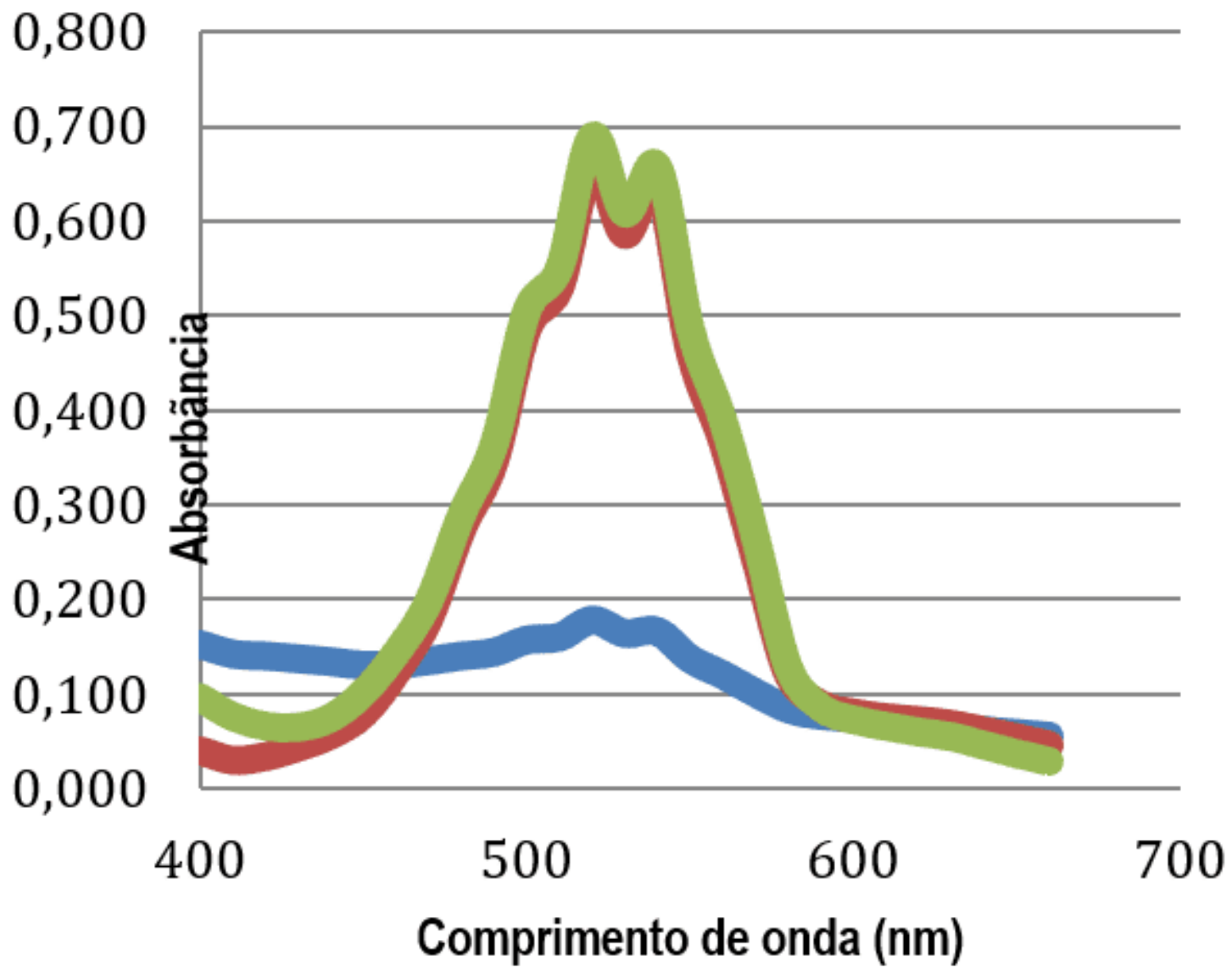

Fonte: o autor (2019)

O resultado da análise da solução estoque (padrão) de permanganato indicou que o máximo de absorção da substância é realmente em $520 \mathrm{~nm}$, como mostra a figura 3. Isso indica que as amostras $A_{1}, A_{2}, C_{1}, C_{2}, D_{1}$ e $D_{2}$ possuem permanganato. Os resultados diferentes entre as quatro amostras (com absorbâncias diferentes) são decorrente das diferentes concentrações das mesmas. As absorbâncias acentuadas fora do comprimento de onda máximo de absorção do permanganato indicam a presença de impurezas que absorvem em comprimentos de onda diferentes. 
Figura 3: Comprimento de onda de máxima absorbância para o permanganato.

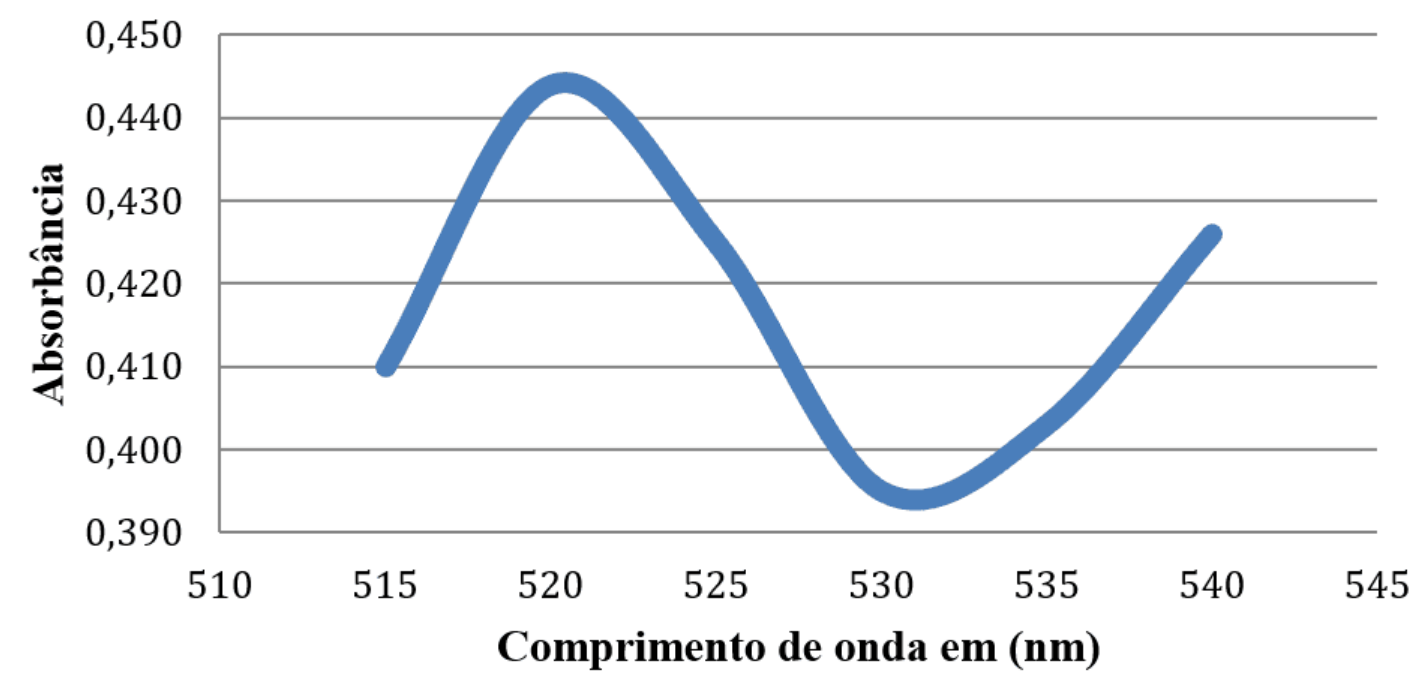

Fonte: o autor (2019)

Analisando a solução estoque de permanganato de potássio (gráfico 4) em cinco concentrações diferentes $\left(5,0 \times 10^{-5}\right.$ mol.L-1; $; 1,0 \times 10^{-4}$ mol.L-1; $; 2,0 \times 10^{-4}$ mol.L-1; $3,0 \times$ $10^{-4}$ mol.L-1 e 4,0 $\times 10^{-4}$ mol..-1) e obtendo suas respectivas absorbâncias, foi possível construir a curva de calibração e encontrar a absortividade molar do $\mathrm{MnO}_{4}^{-}$, para a partir do resultado, poder encontrar as concentrações aproximadas de íon permanganato nas soluções das amostras $A_{1}, A_{2}, C_{1}, C_{2}, D_{1}$ e $D_{2}$. A curva de calibração foi feita com concentração versus absorbância e pela equação da reta obteve-se o valor da absortividade molar, $\delta$, do permanganato, como mostra a figura 4. $O$ coeficiente de determinação, $R^{2}$, apresentou-se adequado. $O$ valor de $\Sigma$ encontrado foi $2.038,00 \mathrm{~mol}^{-1}$.L.cm ${ }^{-1}$. 
Figura 4: Curva de calibração para a solução estoque de $\mathrm{MnO}_{-4}$ em $520 \mathrm{~nm}$.

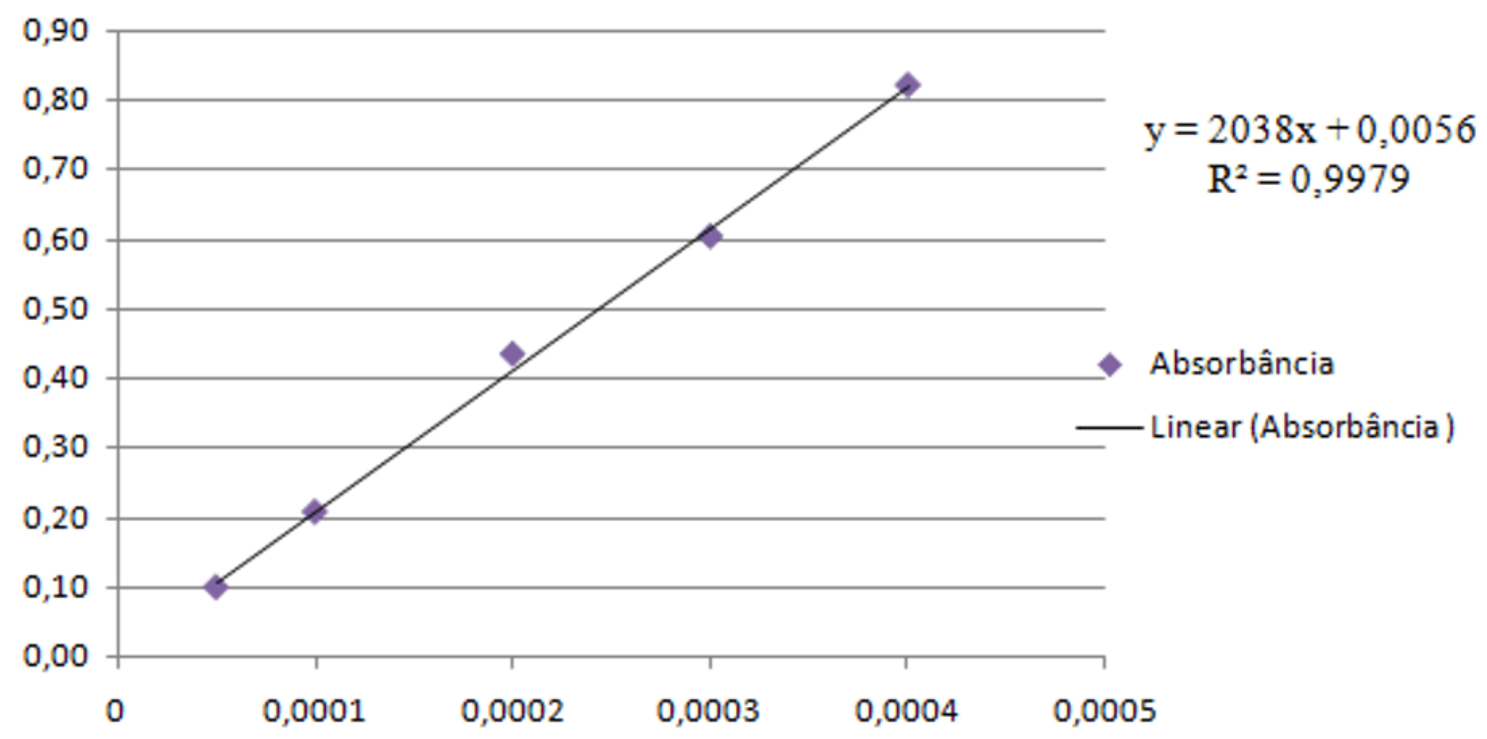

Fonte: o autor (2019)

Analisando a figura $4 \mathrm{e}$ considerando a lei de Lambert-Bee, que mostra que o processo no qual a quantidade de luz absorvida ou transmitida por uma determinada solução depende da concentração do soluto e da espessura da solução (MANTE e DINIZ, 2017). Utilizou-se a relação $A=\sum$.b.C para chegar as concentrações aproximadas de permanganato nas soluções $A_{1}, A_{2}, C_{1}, C_{2}, D_{1}$ e $D_{2}$. Aplicando a fórmula e considerando as diluições feitas, foram obtidas as seguintes concentrações aproximadas de $\mathrm{MnO}_{4}{ }^{-}$nas amostras: $\mathrm{A}_{1}: 8,1 \times 10^{-5}$ mol.L-1; $\mathrm{C}_{1}: 1,2 \times 10^{-4} \mathrm{~mol} . \mathrm{L}^{-1}$; $D_{1}: 1,83 \times 10^{-3}$ mol.L-1 $; A_{2}: 8,7 \times 10^{-5}$ mol.L-1; $C_{2}: 3,2 \times 10^{-4}$ mol.L-1 e $D_{2}: 3,24 \times 10^{-4}$ mol. $\mathrm{L}^{-1}$. Posteriormente foram obtidos resultados com concentrações maiores.

Por aquecimento a $850^{\circ} \mathrm{C}$ da pasta eletrolítica com hidróxido de potássio gera melhores resultados sem a adição de nitrato de sódio, o oxigênio do ar parece ser suficiente para que a oxidação ocorra. As soluções derivadas dos conteúdos dos cadinhos que continham $\mathrm{NaHCO}_{3}$ apresentaram maior concentração de permanganato, isso indica que a solução de bicarbonato de sódio gera melhores resultados na oxidação de manganês VI a manganês VII do que a solução concentrada de ácido sulfúrico, além de apresentar menor custo. Tratar previamente 
a pasta eletrolítica com solução concentrada de $\mathrm{KOH}$ antes de aquecer com $\mathrm{KOH}$ sólido leva a um rendimento melhor para obtenção de solução de permanganato.

Figuras 5 e 6: Soluções de permanganato obtidas pelo método em estudo.
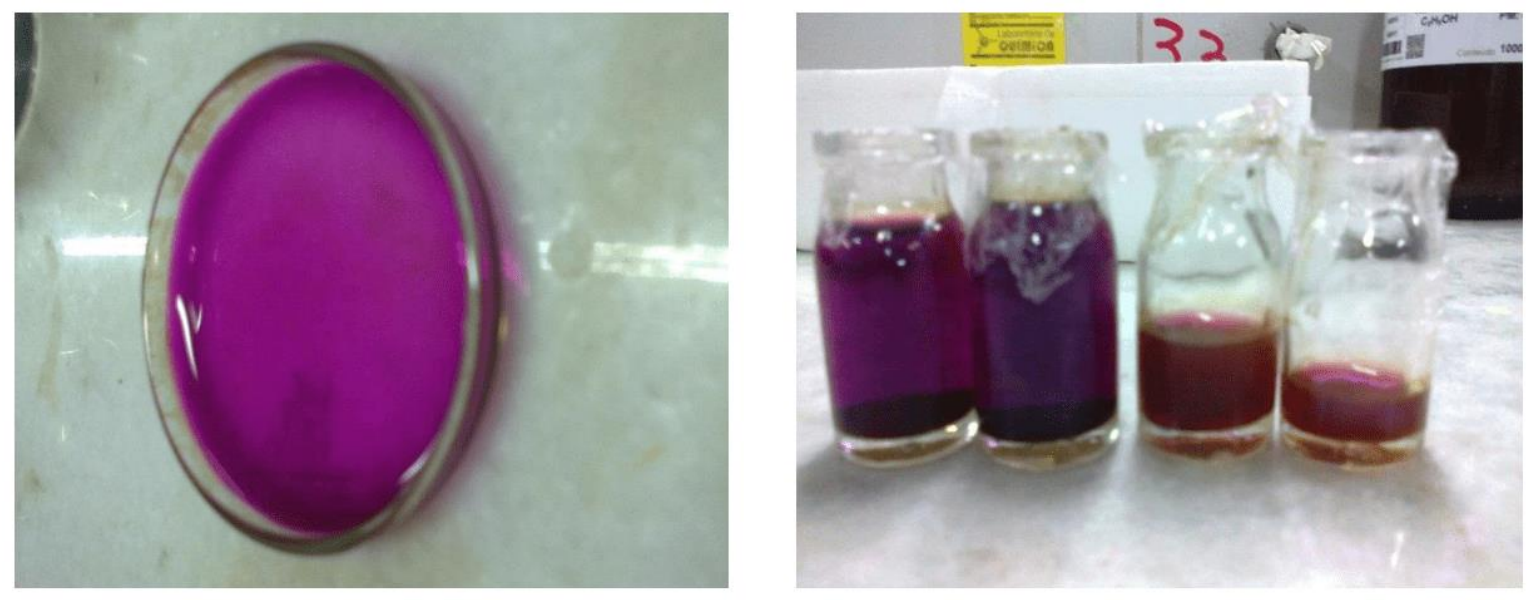

Fonte: autor.

\subsection{LIOFILIZAÇÃO}

A liofilização é o processo de desidratação de produtos, seja para tornar-se um produto menos perecível, seja para separar a água de outros componentes de determinada mistura. Esse processo envolve três etapas: congelamento, secagem primária e secagem secundária. Para ser liofilizado, o produto precisa ser primeiramente congelado a uma temperatura bem baixa, preferencialmente menor que $-20^{\circ} \mathrm{C}$ (TERRONI et al. 2013; PITOMBO, 1989).A finalidade do congelamento dentro do processo de liofilização consiste na imobilização do produto a ser liofilizado, interrompendo reações químicas e atividades biológicas. Uma vez congelado, o material é desidratado por sublimação seguida de dessorção. O processo de congelamento é determinante tanto para a taxa de sublimação quanto para estrutura e forma do produto. A estrutura do produto não deve ser alterada durante o processo, evitando a ocorrência de danos (TATTINI Jr et al., 2006).

A liofilização da solução obtida de permanganato de potássio, quando $\circ \mathrm{MnO}_{2}$ foi fundindo juntamente com $\mathrm{KOH}$ e que teve a oxidação de manganês VI a VII por 
solução de ácido sulfúrico, obteve-se bom resultado. Depois que a desidratação do material foi concluída, restou um sólido apresentando o sal $\mathrm{KMnO}_{4}$ com pureza aproximada de $15 \%$.

\section{CONSIDERAÇÕES FINAIS}

Tendo em vista os resultados obtidos, percebe-se que o método de tratamento da pasta eletrolítica de pilhas alcalinas e zinco-carbono para converter o óxido de manganês em permanganato, obtendo soluções do íon, mostrou-se adequado, de baixo custo e de bom rendimento. Pela concentração obtida na amostra que mostrou melhor resultado $\left(D_{2}\right)$, pode-se esperar obter um rendimento de aproximadamente $25 \%$ em massa de permanganato de potássio pelo tratamento da pasta eletrolítica de cada pilha $\mathrm{D}$ zinco-carbono, usando esse método. Considerando que a porcentagem de dióxido de manganês na pasta eletrolítica de uma pilha nova varia de 20 a 30\% em massa, esse é um bom resultado.

Por outro lado, a liofilização da solução mais concentrada de permanganato de potássio obtida a partir do dióxido de manganês de pilhas leva a obtenção do sal sólido com pureza aproximada de 15\%. Desse modo, seria viável estudar o desenvolvimento de uma técnica que leve à obtenção do $\mathrm{KMnO} 4$ sólido com pureza maior bem como uma maneira de cristalizá-lo, resultados estes não alcançados neste trabalho.

Conclui-se que é possível obter Permanganato de potássio a partir da oxidação do Dióxido de Manganês de pilhas descartadas. Considerando a importância do ponto de vista da sustentabilidade, o método apontado neste trabalho é importante por mostrar uma alternativa para o reaproveitamento de componente de pilhas que perderam sua utilidade e na maioria das vezes são descartadas de maneira irregular, poluindo o meio ambiente.

\section{REFERÊNCIAS}

AFONSO, J. C., et al. Processamento da pasta eletrolítica de pilhas usadas. Química Nova 26.4, 2003. 
ARAUJO, H. R. Eletro-oxidação de glicerol em eletrodos de Pt e PtRh em meio ácido: estudo da variação da temperatura e da composição de catalisadores. Dissertação de mestrado ao programa de pós graduação em Química da UFMA, São Luiz, 2013.

CAMPIOTTI, A. T. e GIORDANO, J. B. utilização de produtos à base de reciclagem de pilhas na área têxtil. Revista Tecnológica da FATEC Americana, 2015.

DA ROCHA, R. A.; AFONSO, J. C. Manganês. Vol. 34, № 2 (2012), p. 103-105. Mäntele, Werner, and Erhan Deniz. UV-VIS absorption spectroscopy: LambertBeer reloaded. 2017.

PITOMBO, R. N. M. A liofilização como técnica de conservação de material de pesquisa. Ciên Cult 41, 1989.

PRATES, H. M., et al. Teores elevados de manganês em amostras de solos. Fórum Ambiental da Alta Paulista, 2011.

RASCIO, D. C., et al. Reaproveitamento de óxidos de manganês de pilhas descartadas para eletrocatálise da reação de redução de oxigênio em meio básico. Quimica Nova 33.3, 2018.

SILVA, VITOR ROGÉRIO PEREIRA RIBEIRO DA; ANDRADE, LUCIANA PAES DE. Ações de educação ambiental, voltadas para o correto descarte de pilhas e baterias, no cenário universitário. 2018.

TABELA PERIÓDICA COMPLETA. (2016). Manganês. Disponível em: $<$ http://www.tabelaperiodicacompleta.com/elemento-quimico/manganes>. Acesso em 17 de março de 2016.

TATTINI, V. J., Duclerc Fernandes Parra, e R. N. M. Pitombo. Influência da taxa de congelamento no comportamento físico-químico e estrutural durante a liofilização da albumina bovina. Brazilian J Pharm Sci, 2006. 
TERRONI EQUIPAMENTOS CIENTÍFICOS LTDA. (s.d.). O que é liofilização. Disponível em: < http://www.terroni.com.br/o-que-e-liofilizacao/>. Acesso em 10 de maio de 2016.

VIANA, J. Eco amigos, no wordprees, 2008. Disponível em: https://ecoamigos.wordpress.com/2008/10/20/lixo-tecnologico/. Acessado em 20 de maio de 2016.

VIEIRA, L. H. C., SILVA, R. G., SILVA, B. O., JÚNIOR, S. S. H., CÂMARA, S. C., AFONSO, J. C. Avaliação da qualidade de pilhas alcalinas e zinco-carbono de diferentes procedências. Eclética química, 2013.

ZORZANELLI, Bruna C.; MURI, Estela MF. Oxidação de Alcoóis em Química Verde. Revista Virtual de Química, v. 7, n. 2, p. 663-683, 2015.

Enviado: Fevereiro, 2020.

Aprovado: Agosto, 2020. 